\title{
Biofilm model calibration and microbial diversity study using Monte Carlo simulations
}

\author{
D. Brockmann, A. Caylet, R. Escudié, N. Bernet, J.-P. Steyer \\ INRA, UR0050, Laboratoire de Biotechnologie de l'Environnement, Avenue des Etangs, Narbonne, F- \\ 11100, France \\ (E-mail: doris.brockmann@supagro.inra.fr, renaud.escudie@supagro.inra.fr, \\ nicolas.bernet@supagro.inra.fr, Jean-Philippe.Steyer@supagro.inra.fr)
}

\begin{abstract}
A single specie biofilm model was used to describe aerobic glucose degradation at $45^{\circ} \mathrm{C}$ in a biofilm reactor operated at three different hydraulic retention times (HRT). The model was calibrated to experimental data using the Monte Carlo filtering method. Eleven parameter sets out of 500 properly described the biofilm reactor performance for the three HRTs studied. After calibration, the single specie biofilm model was extended to a model with 10 different heterotrophic bacteria for studying microbial diversity in bulk phase and biofilm, as well as the competition between suspended and attached biomass. Independent of the HRT, the dominating and only remaining bacterial group in steady state was the same for bulk phase and biofilm. The dominating bacterial group was determined by the highest specific substrate affinity (ratio of $\mu / \mathrm{K}_{\mathrm{S}}$ ) of all considered bacterial groups. At a short HRT of 20 minutes, the microbial community in the bulk liquid was considerably influenced by biomass detachment from the biofilm, whereas both biomass detachment from the biofilm and microbial growth in the bulk liquid influenced the microbial community at a long HRT of 8 hours.
\end{abstract}

Keywords

Biofilm; calibration; microbial diversity; model; Monte Carlo simulation

\section{INTRODUCTION}

Mathematical models are useful tools for studying and exploring biochemical processes as well as microbial competition and coexistence. For adequately representing experimental data with a mathematical model, calibration of the model to collected data is inevitable. When experiments are run under conditions not typical for wastewater treatment (e.g. at higher temperatures), typically little information on possible kinetic parameter values is available from literature. In such cases, methods considering parameter ranges rather than a small area around the initial parameter values can help determining appropriate sets of parameter values. Global sensitivity analysis methods and screening methods are classical tools for evaluating parameter sensitivity based on parameter ranges and identifying parameters to be estimated (Saltelli et al., 2000). For estimation of the selected parameters, however, adequate initial parameter values are still needed. In contrast, the Monte Carlo filtering method developed by Spear and Hornberger (1980) enables the determination of parameter sets properly describing the observed system/reactor behavior from given initial ranges of parameter values. This is of particular interest when a good initial guess of the initial parameter values is difficult because, for example, extrapolation of rate constants is not suitable. In addition, the Monte Carlo filtering method can also be used when only scarce experimental data are available (Spear and Hornberger, 1980) that are not sufficient for parameter estimation using optimization procedures.

In this study, we used the Monte Carlo filtering method to calibrate a single specie biofilm model to experimental data of a biofilm reactor degrading glucose at a temperature of $45^{\circ} \mathrm{C}$ and different hydraulic retention times (HRT). The calibrated parameter values were used as starting point for studying microbial population dynamics in the reactor with a multi-species biofilm model considering 10 different heterotrophic bacteria. 


\section{MATERIALS AND METHODS}

\section{Biofilm reactor}

An annular biofilm reactor (model 1320 LI, BioSurface Technologies Corp., Bozeman, MT, USA) was operated for periods of 6 weeks at 50 rotations per minute. The reactor was equipped with a water jacket and operated at a controlled temperature of $45^{\circ} \mathrm{C}$. The reactor was aerated by introducing air to an aeration chamber located in the recirculation line (Figure 1). The experimental setup had an overall liquid volume of $1.2 \mathrm{~L}$ (annular reactor + aeration chamber + recirculation line) and an estimated overall surface area of $0.252 \mathrm{~m}^{2}$ (surface area in annular reactor + potential wall growth in aeration chamber and recirculation line). A glucose rich synthetic wastewater $(2 \mathrm{~g}$ glucose $/ \mathrm{L})$ was fed to the reactor at a constant surface loading rate of $24 \mathrm{~g}$ glucose $/\left(\mathrm{m}^{2} \cdot \mathrm{d}\right)$. The flow rate of the dilution water varied depending on the desired hydraulic retention time (HRT). Three experiments with different HRTs of $20 \mathrm{~min}, 1$ hour, and 8 hours were carried out to evaluate the impact of hydraulic conditions on the competition between suspended and attached biomass as well as on the microbial diversity of suspended and attached biomass. The reactor was inoculated with $100 \mathrm{~mL}$ white water from the paper mill Voiron in Grenoble, France, and operated in batch mode for 24 hours. After 24 hours, the reactor was switched to continuous mode and the experiments started. Every week, glucose and mixed liquor suspended solids (MLSS) concentrations in the effluent as well as biofilm density and biofilm thickness were measured. In addition, the microbial communities in bulk liquid and biofilm was analyzed every week using a culture independent approach based on single-strand conformation polymorphism (SSCP) analysis of total 16S rDNA amplification products (Wery et al., 2008).

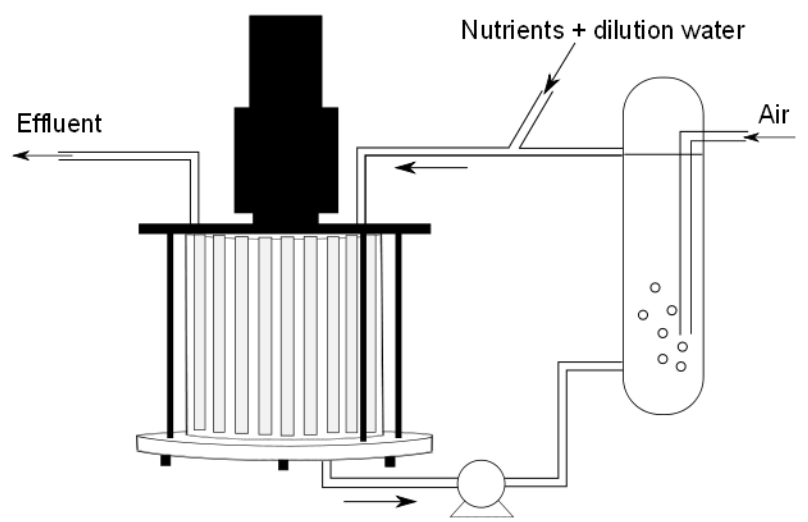

Figure 1: Annular reactor set-up with recirculation line and aeration chamber.

\section{Mathematical model}

A single specie biofilm model was developed for model calibration. The model considered growth, aerobic endogenous respiration, and decay of heterotrophic bacteria in both biofilm and bulk phase. Growth was described with double Monod kinetics for substrate and dissolved oxygen. Endogenous respiration was modeled with Monod kinetics for dissolved oxygen, and decay was described as first order process. When modeling microbial growth in both bulk liquid and biofilm, it is important to take into account that activated sludge models use apparent half-saturation constants that (implicitly) account for diffusion through the activated sludge floc (Beccari et al., 1992; Daigger et al., 2007; Perez et al., 2005), while biofilm models consider diffusion within the biofilm separately. As a consequence, values for half-saturation constants used in activated sludge models will be higher than the values for half-saturation constants used in biofilm models. To account for this difference, a factor $\alpha$ was introduced and multiplied with the half-saturation constants in the differential equations for growth and aerobic endogenous respiration in the bulk liquid (instead of $\mathrm{S} /\left(\mathrm{K}_{\mathrm{S}}+\mathrm{S}\right)$ and $\mathrm{S}_{\mathrm{O} 2} /\left(\mathrm{K}_{\mathrm{O} 2}+\mathrm{S}_{\mathrm{O} 2}\right), \mathrm{S} /\left(\alpha \cdot \mathrm{K}_{\mathrm{S}}+\mathrm{S}\right)$ and $\mathrm{S}_{\mathrm{O} 2} /\left(\alpha \cdot \mathrm{K}_{\mathrm{O} 2}+\mathrm{S}_{\mathrm{O} 2}\right)$ were used $)$. The value of $\alpha$ will be $\geq 1$ and will depend on the size of the activated sludge flocs in the bulk liquid. The range for $\alpha$ was arbitrarily chosen to be 1 to 10 . 


\section{Model calibration}

We used the Monte Carlo filtering method (Spear and Hornberger, 1980) for calibrating the single specie biofilm model for three different HRTs because only few data points were available for each experiment and because the biofilm reactor was operated at a temperature $\left(45^{\circ} \mathrm{C}\right)$ not typical for wastewater treatment. The Monte Carlo filtering method consists of a qualitative definition of the system/reactor behavior and a subsequent binary classification of the model outputs of Monte Carlo simulations based on the defined system behavior. We based the definition of the desired system behavior on effluent substrate and MLSS concentrations observed in the three experiments with different HRTs. The constraints for effluent substrate and MLSS concentrations defining the desired system behaviour for each studied HRT are given in Table 1.

Table 1: Desired system behavior defined for each HRT for day 42 of the experiment/simulation based on experimental data

\begin{tabular}{lcc}
\hline HRT & $\begin{array}{c}\text { Effluent glucose concentration } \\
{[\mathrm{mg} \mathrm{COD} / \mathrm{L}]}\end{array}$ & $\begin{array}{c}\text { Effluent MLSS concentration } \\
{[\mathrm{mg} \text { MLSS/L] }}\end{array}$ \\
\hline 20 min & $5 \leq \mathrm{S}_{\mathrm{S} \text {,desired }} \leq 15$ & $15 \leq \mathrm{X}_{\mathrm{MLSS}, \text { desired }} \leq 60$ \\
1 hour & $5 \leq \mathrm{S}_{\mathrm{S} \text {,desired }} \leq 15$ & $40 \leq \mathrm{X}_{\mathrm{MLSS}, \text { desired }} \leq 80$ \\
8 hours & $5 \leq \mathrm{S}_{\mathrm{S} \text {,desired }} \leq 10$ & $400 \leq \mathrm{X}_{\mathrm{MLSS} \text {,desired }} \leq 800$ \\
\hline
\end{tabular}

A parameter vector resulting in simulation results complying with the constraints for effluent substrate and biomass concentrations for all three studied HRTs was classified as "behavior". For all parameter vectors classified as "behavior", two-sample Kolmogorov-Smirnov tests were carried out independently for each parameter in order to identify the parameters that are significant for obtaining acceptable model results ("behavior"). Parameters altered during Monte Carlo simulations included all kinetic and stoichiometric parameters related to heterotrophic bacteria $\left(\mu_{\mathrm{H}}, \mathrm{K}_{\mathrm{S}, \mathrm{H}}, \mathrm{b}_{\mathrm{H}}, \mathrm{d}_{\mathrm{H}}\right.$, $\left.\mathrm{K}_{\mathrm{O} 2 \mathrm{H}}, \mathrm{Y}_{\mathrm{H}}\right)$ as well as the mass transfer boundary layer thickness $\left(\mathrm{L}_{\mathrm{L}}\right)$, the biofilm density $\left(\rho_{\mathrm{X}}\right)$, the biofilm surface area $\left(\mathrm{A}_{\mathrm{f}}\right)$, the liquid volume fraction of the biofilm $\left(\varepsilon_{1}\right)$, and $\alpha$. Parameter ranges are given in Table 2. All varied parameters were described by uniform distributions. A parameter sample of size 500 was drawn from the parameter space using Latin hypercube sampling. Simulations were carried out using AQUASIM (Reichert, 1998). R (R Development Core Team, 2010) was used for post-processing of simulation data.

Table 2: Parameters considered for model calibration: parameter ranges, initial/measured values, and values of the selected calibrated parameter set. Values for rate constants are given for $20^{\circ} \mathrm{C}$.

\begin{tabular}{|c|c|c|c|c|c|}
\hline Description & Symbol & Unit & Range & $\begin{array}{c}\text { initial/ } \\
\text { measured }^{(*)}\end{array}$ & $\begin{array}{l}\text { Calibrated and } \\
\text { selected }\end{array}$ \\
\hline Maximum growth rate & $\mu_{\mathrm{H}}$ & $1 / \mathrm{d}$ & $10-25$ & 22 & 24.57 \\
\hline $\begin{array}{l}\text { Half-saturation constant for } \\
\text { substrate }\end{array}$ & $\mathrm{K}_{\mathrm{S}, \mathrm{H}}$ & $\mathrm{g} \mathrm{COD} / \mathrm{m}^{3}$ & $1-20$ & 20 & 13.08 \\
\hline Endogenous respiration rate & $b_{\mathrm{H}}$ & $1 / \mathrm{d}$ & $0.1-1$ & 0.2 & 0.54 \\
\hline Decay rate & $\mathrm{d}_{\mathrm{H}}$ & $1 / \mathrm{d}$ & $0.05-0.5$ & 0.05 & 0.50 \\
\hline Half-saturation constant for oxygen & $\mathrm{K}_{\mathrm{O} 2, \mathrm{H}}$ & $\mathrm{g} \mathrm{COD} / \mathrm{m}^{3}$ & $0.1-0.5$ & 0.5 & 0.46 \\
\hline Biomass yield & $\mathrm{Y}_{\mathrm{H}}$ & $\begin{array}{l}\mathrm{g} \mathrm{COD}_{\mathrm{X}} / \\
\mathrm{g} \mathrm{COD}\end{array}$ & $0.42-0.67$ & $0.42^{(*)}$ & 0.44 \\
\hline External boundary layer thickness & $\mathrm{L}_{\mathrm{L}}$ & $\mu \mathrm{m}$ & $10-50$ & 50 & 11 \\
\hline Biofilm density & $\rho_{\mathrm{X}}$ & $\mathrm{g} \mathrm{COD} / \mathrm{m}^{3}$ & $10,000-20,000$ & $19,000^{(*)}$ & 18,485 \\
\hline Biofilm surface area & $\mathrm{A}_{\mathrm{f}}$ & $\mathrm{m}^{2}$ & $0.2-0.3$ & $0.252^{(*)}$ & 0.237 \\
\hline Liquid volume fraction & $\varepsilon_{1}$ & - & $0.7-0.95$ & 0.8 & 0.75 \\
\hline $\begin{array}{l}\text { Correction factor for half- } \\
\text { saturation constants }\end{array}$ & $\alpha$ & - & $1-10$ & 1 & 3.87 \\
\hline
\end{tabular}




\section{Studying microbial diversity}

In order to study the microbial diversity in biofilm and bulk phase, we extended the calibrated single specie biofilm model to a model with 10 heterotrophic bacteria using glucose as electron donor. Only $\mu_{\max }$ and $K_{S}$ were altered from bacterial group to bacterial group while keeping all other kinetic and stoichiometric parameters the same. As in Ramirez et al. (2009), the parameter values for $\mu_{\max }$ and $\mathrm{K}_{\mathrm{S}}$ were randomly chosen from two normal distributions with means of $\mu_{1}=0.6 \cdot \mathrm{k}$ and $\mu_{2}=1.4 \cdot \mathrm{k}$, and standard deviations of $\sigma_{1,2}=0.125 \cdot \mathrm{k}$, with $\mathrm{k}$ being the calibrated parameter value of the single specie biofilm model. Five bacterial groups are modeled as Kstrategists combining low $\mathrm{K}_{\mathrm{S}}$ values with low $\mu$ values, the other five bacterial groups are modeled as $\mu$-strategists combining high $\mathrm{K}_{\mathrm{S}}$ values with high $\mu$ values. Simulations were run for 100 different sets of parameter values for HRTs of 20 minutes and 8 hours.

We used the Simpson's reciprocal index to quantify the diversity of the microbial communities. Simpson's reciprocal index was calculated as follows:

$$
\frac{1}{D}=\frac{1}{\sum_{i=1}^{n} p_{i}(t)^{2}}
$$

where $p_{i}(t)$ is the biomass fraction of bacterial group $i$ at a given time instant $t$.

The large difference between the means of the two normal distributions used for creating the parameter sample allows reaching a biofilm biomass steady state within about 500 days of simulation. Using normal distributions with means that are much closer will result in similar results, but more days have to be simulated in order to reach a steady state of the biomass distribution in the biofilm.

\section{RESULTS AND DISCUSSION \\ Model calibration}

Out of 500 parameter sets, only 11 parameter sets complied with the defined constraints for effluent substrate and MLSS concentrations for all three HRTs evaluated and were classified as "behavior". The heterotrophic growth yield $\left(\mathrm{Y}_{\mathrm{H}}\right)$ and the external boundary layer thickness $\left(\mathrm{L}_{\mathrm{L}}\right)$ had a significant impact on the model results (significance levels $\alpha<1 \%$ ). The biofilm density ( $\left.\rho_{\mathrm{X}}\right)$ had an important influence on the model results (significance level $1 \%<\alpha<10 \%$ ), whereas all other parameters did not have a considerable influence (significance levels $\alpha>10 \%$ ).
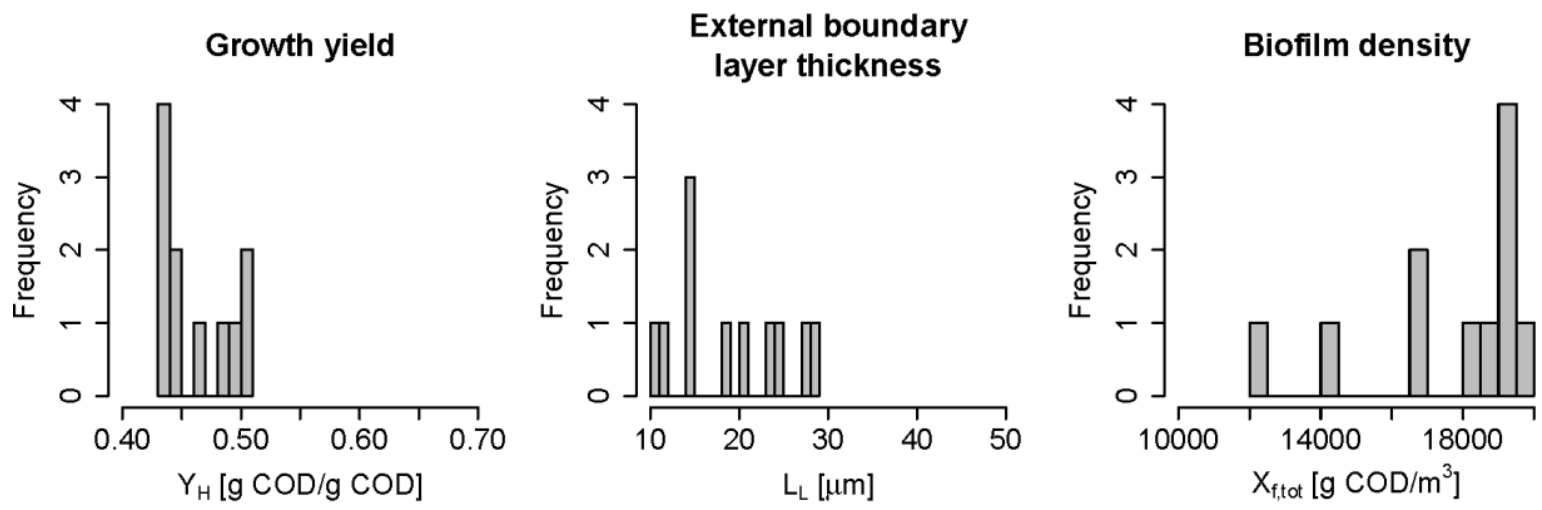

Figure 2: Histograms of the parameter values of the three significant/important parameters of the 11 parameter sets properly describing reactor operation under the three different HRTs.

Figure 2 shows histograms of the parameter values of $\mathrm{Y}_{\mathrm{H}}, \mathrm{L}_{\mathrm{L}}$, and $\rho_{\mathrm{X}}$ of the 11 parameter sets resulting in acceptable model results. The values for $Y_{H}$ ranged from 0.43 to $0.51 \mathrm{~g} \mathrm{COD} / \mathrm{g}$ COD 
with a maximum of 4 parameter values in the range of 0.43 to $0.44 \mathrm{~g} \mathrm{COD} / \mathrm{g}$ COD, which is close to the measured value of $0.42 \mathrm{~g} \mathrm{COD} / \mathrm{g} \mathrm{COD}$. The values for $\mathrm{L}_{\mathrm{L}}$ were also at the lower end of the defined parameter range $(10-50 \mu \mathrm{m})$ with a peak of three values between 14 and $15 \mu \mathrm{m}$. For the biofilm density, the values were rather at the high end of the parameter range (10000-20000 $\mathrm{g}$ $\mathrm{COD} / \mathrm{m}^{3}$ ). A maximum of four values ranged between 19000 and $19500 \mathrm{~g} \mathrm{COD} / \mathrm{m}^{3}$ close to the measured value of $19000 \mathrm{~g} \mathrm{COD} / \mathrm{m}^{3}$. From the 11 parameter sets resulting in acceptable model results, one parameter set was selected as default/base parameter set for the microbial diversity study. The parameter values of the selected parameter set are given in Table 2.

\section{Microbial diversity}

Microbial diversity was studied using the multi species biofilm model with 10 different heterotrophic bacteria that was introduced above. At the end of the experiments (day 42), a higher microbial diversity in the biofilm was observed for an HRT of 8 hours compared to an HRT of 20 minutes based on Simpson's reciprocal diversity index estimated from the molecular fingerprints. The model predicted a slightly higher microbial diversity in the biofilm for an HRT of 8 hours compared to an HRT of 20 minutes, but only for the first three days (Table 3). Then, the microbial diversity in the biofilm was similar for both HRTs. In addition, at steady state (day 500), only one bacterial group remained in biofilm and bulk liquid independent of the HRT. The dominating bacterial group was the same for biofilm biomass and suspended biomass.

Table 3: Simpson's reciprocal index and type of dominating biomass group: For the type of dominating bacterial group, the number of simulations (out of 100) resulting in the specified type of dominating bacterial group is given. Values are provided for different time instants and HRTs of 20 minutes and 8 hours (480 minutes).

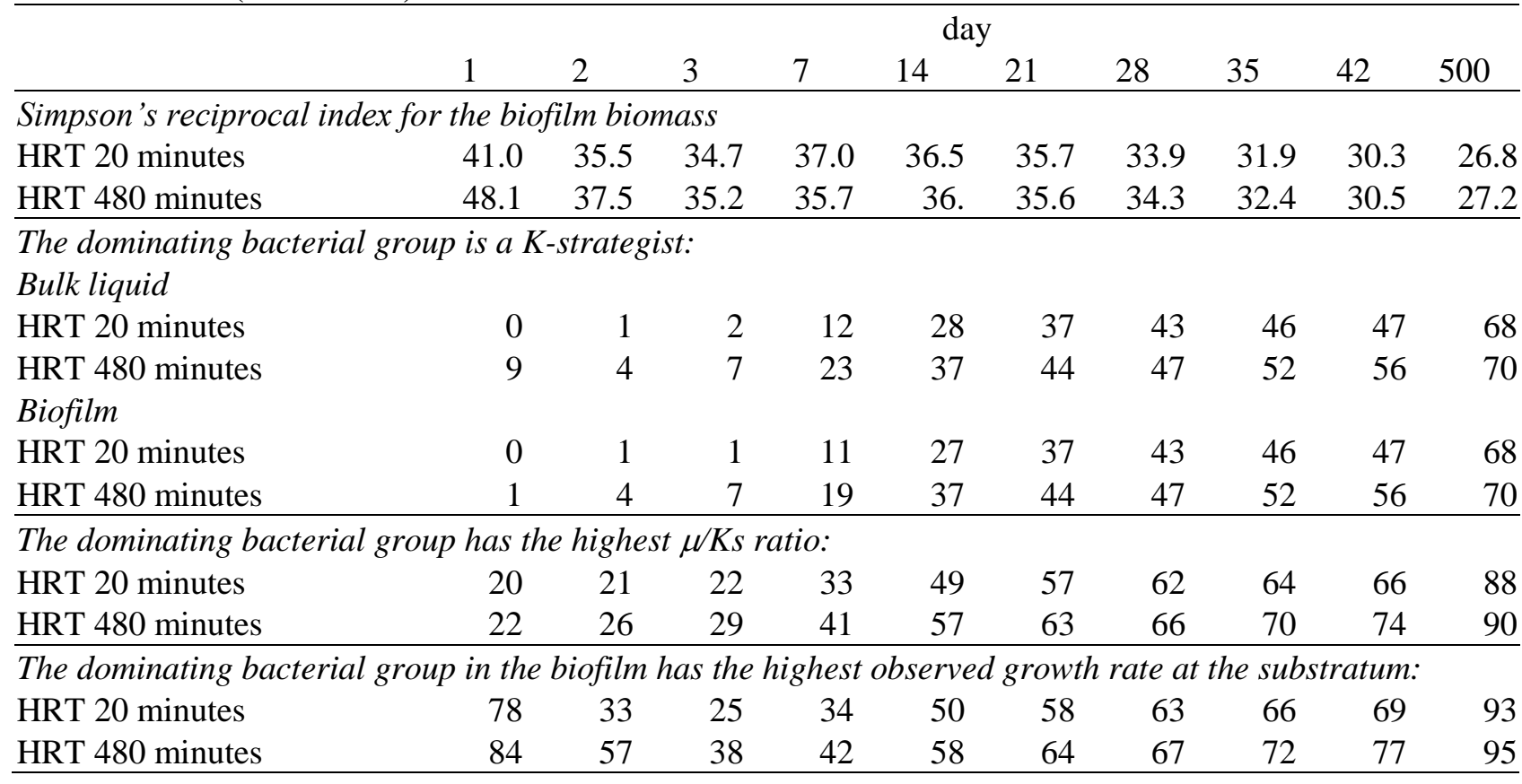

During the first five weeks of simulation (till day 35), the dominating bacterial group in the bulk liquid and in the biofilm was in more than $50 \%$ of the simulations a $\mu$-strategist (Table 3 ). From day 42 on, under more stable environmental conditions, the dominating bacterial group was in the majority of the simulations a K-strategist. At day 500 (quasi steady state), K-strategists dominated in $70 \%$ of the simulations both biofilm and bulk liquid. These observations are consistent with the concept of $\mu$ - and K-selection in microbial ecology, according to which $\mu$-strategists dominate under unstable environmental conditions requiring high growth rates for survival, and K-strategists 
dominate stable environments where they are able to compete for limited amounts of substrate (Andrews and Harris, 1986).

In contrast to the $\mu$ - and $\mathrm{K}$-selection criterion, the ratio of $\mu / \mathrm{K}_{\mathrm{S}}$ was a more distinct criterion for determining the dominating bacterial group as, at day 500, the dominating bacterial group in about $90 \%$ of the simulations (88\% for an HRT of 20 minutes, and $90 \%$ for an HRT of 8 hours) was the one with the highest ratio of $\mu / \mathrm{K}_{\mathrm{S}}$ (Table 3 ). In the other $10 \%$ of the cases, the biomass distribution in the biofilm had not yet reached steady state. Continuing the simulations for these $10 \%$ of the cases until day 1000 (or even longer) resulted in each case in the dominating bacterial group being the one with the highest ratio of $\mu / K_{S}$ (results not shown). The ratio of $\mu / K_{S}$ approximates the initial slope of the Michaelis-Menten (Monod) curve and is a measure of the specific affinity of organisms for substrate (Button and Robertson, 1989). In fact, the initial slope of the Michaelis-Menten curve determines which microorganism will dominate the microbial community in the long term (Nedwell, 1999). Hence, our simulation results agree with these findings from microbial ecology.

In quasi steady state (day 500), the dominating bacterial group in the biofilm was the bacterial group with the highest observed growth rate $\left(\mu_{\text {observed }}\right)$ at the biofilm substratum (Table 3$)$. Starting on day 3 , the number of simulations, in which the dominating bacterial group is the one with the highest observed growth rate at the biofilm substratum, steadily increased with simulation time. Nonetheless, after 500 days of simulation, a steady state of the biomass distribution was not yet reached in all cases. The condition for bacterial coexistence in steady state is $\mu_{\mathrm{observed}, \mathrm{i}}=\mu_{\mathrm{observed}, \mathrm{j}}$ at the biofilm substratum due to the steady state boundary condition at the biofilm-substratum interface of the multi-species biofilm model implemented in AQUASIM (Wanner and Gujer, 1984).

\section{Dynamics in biomass distributions}

Figure 3 shows biomass distributions at the biofilm substratum, at the biofilm surface, and in the bulk liquid for days 1, 3, 7 and 42, and for both evaluated HRTs. The microbial diversity in both biofilm and bulk liquid clearly decreased with increasing time. From day 3 on, both biofilm and

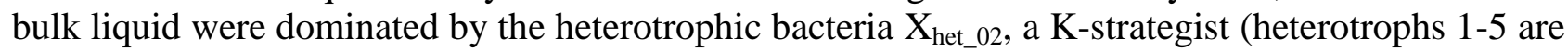
K-strategists, heterotrophs 6-10 are $\mu$-strategists), independent of the HRT. In contrast, at day 1, biofilm and bulk liquid were dominated by a $\mu$-strategist $\left(\mathrm{X}_{\text {het_10 }}\right)$ at a short HRT of 20 minutes, whereas at an HRT of 8 hours, biofilm and bulk liquid are already dominated by the K-strategist

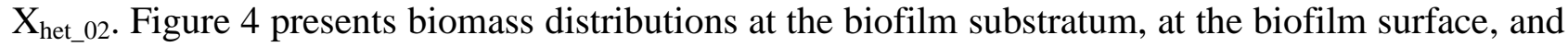
in the bulk liquid for a set of parameter values resulting in a $\mu$-strategist as dominating bacterial group. From the beginning, the $\mu$-strategist $X_{\text {het_07 }}$ dominates biofilm and bulk liquid for both HRTs.

Evaluating Figures 3 and 4 in more detail shows that, at days 3 and 7, the biomass distribution at the biofilm substratum is more divers than at the biofilm surface. At day 1, the biomass distributions at the biofilm substratum and the biofilm surface are similar as the biofilm is too thin for the development of a distinct biomass gradient over the biofilm thickness. At day 42, the biofilm substratum is totally dominated by inert biomass. A higher microbial diversity at the biofilm substratum than at the biofilm surface has been experimentally observed by Rochex et al. (2009). Rochex et al. (2009) also showed that the microbial community of the base layer of the biofilm includes the dominating bacterial group of the top layer. The simulation results properly reflect the observation made by Rochex et al. (2009). However, it needs to be mentioned that the biomass distribution at the biofilm substratum, as presented in Figures 3 and 4, does not reflect the biomass distribution in the first colonized layer above the substratum. Nonetheless, the microbial community in the first colonized layer above a purely inert base of the biofilm, as predicted by the model, included the biomass group dominating the top layer of the biofilm (results not shown). 
Biomass distribution at day 1
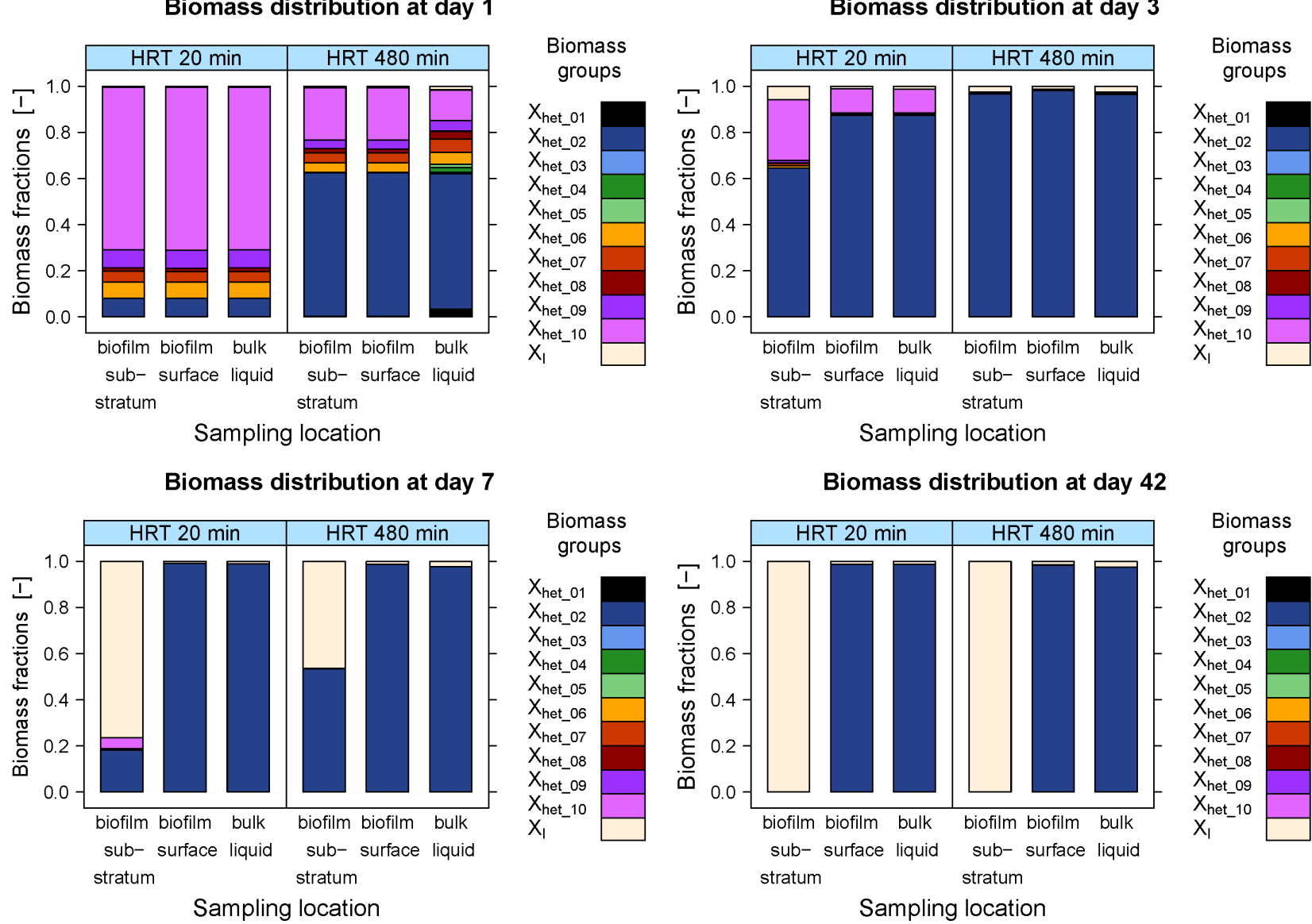

Biomass distribution at day 42

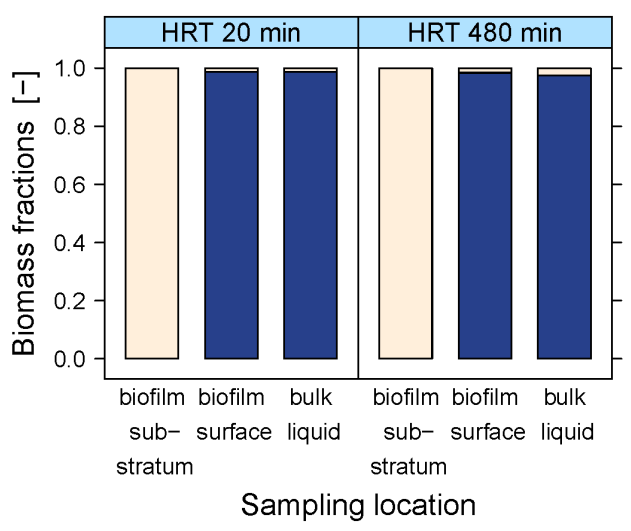

Biomass

groups

Figure 3: Biomass distributions at the biofilm substratum, the biofilm surface, and in the bulk liquid for a $\mathrm{K}$ strategist as dominating bacterial group. Biomass distributions are given for days 1, 3, 7, and 42 (end of the experiment) for HRTs of both 20 minutes and 8 hours (480 minutes). Heterotrophic bacteria 1 to 5 are K-strategists, heterotrophic bacteria 6 to 10 are $\mu$-strategists.

At a short HRT of 20 minutes, the biomass composition in the bulk liquid was very similar to the biomass composition at the surface of the biofilm. At this short HRT, bacterial growth in the bulk liquid is hardly possible at growth rates of $14.7 \mathrm{~d}^{-1}$ on average for K-strategists and $34.4 \mathrm{~d}^{-1}$ on average for $\mu$-strategists. Consequently, the microbial community in the bulk liquid is primarily determined by detachment of biomass from the biofilm surface. In contrast, at longer HRTs (here 8 hours), the biomass compositions in the bulk liquid and at the biofilm surface were different. At an HRT of 8 hours, bacterial growth in the bulk liquid is possible and, as a consequence, the microbial community in the bulk liquid is influenced by both growth of bacteria in the bulk liquid and detachment of biomass from the biofilm surface. Furthermore, at a long HRT of 8 hours, the biomass steady state in the biofilm is reached faster than at a short HRT of 20 minutes.

\section{CONCLUSIONS}

1. Monte Carlo filtering allowed identifying 11 sets of parameter values that adequately represented experimental data for the three different HRTs of 20 minutes, 1 hour, and 8 hours.

2. Independent of the HRT, the dominating and only remaining bacterial group in steady state was the same for bulk phase and biofilm. The dominating bacterial group was not determined based on the $\mu$ - and K-selection criterion but based on the specific affinity (ratio of $\mu / K_{S}$ ). The dominating bacterial group had the highest specific affinity of all considered bacterial groups.

3. At short HRTs, the microbial community in the bulk liquid is primarily determined by detachment of biomass from the biofilm surface. In contrast, at long HRTs, both bacterial 
growth in the bulk liquid and detachment of biomass from the biofilm surface influence the microbial community in the bulk liquid.

Biomass distributions at day 1

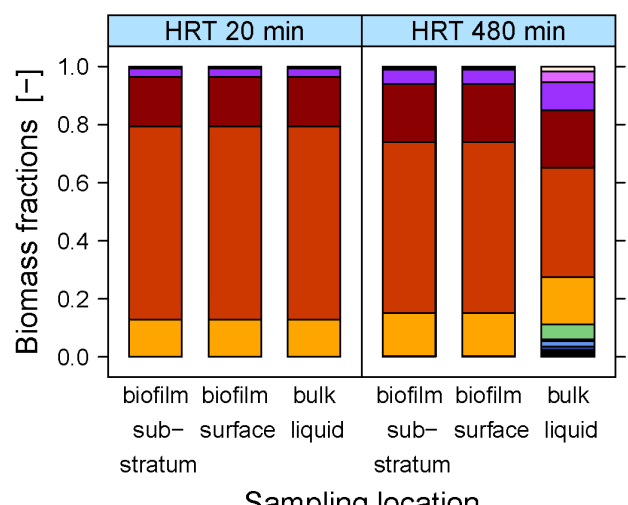

Sampling location

Biomass distributions at day 7

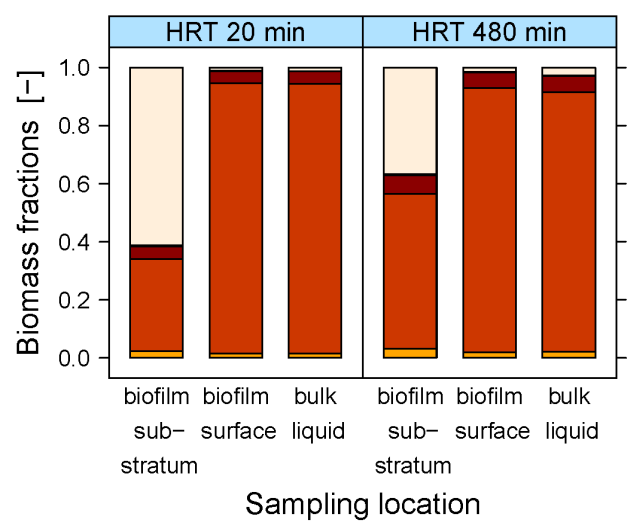

Biomass distributions at day 3
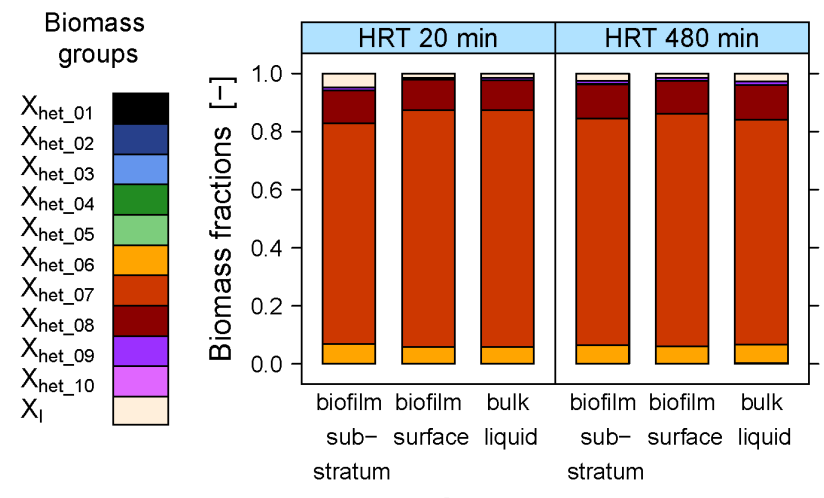

Sampling location

Biomass distributions at day 42
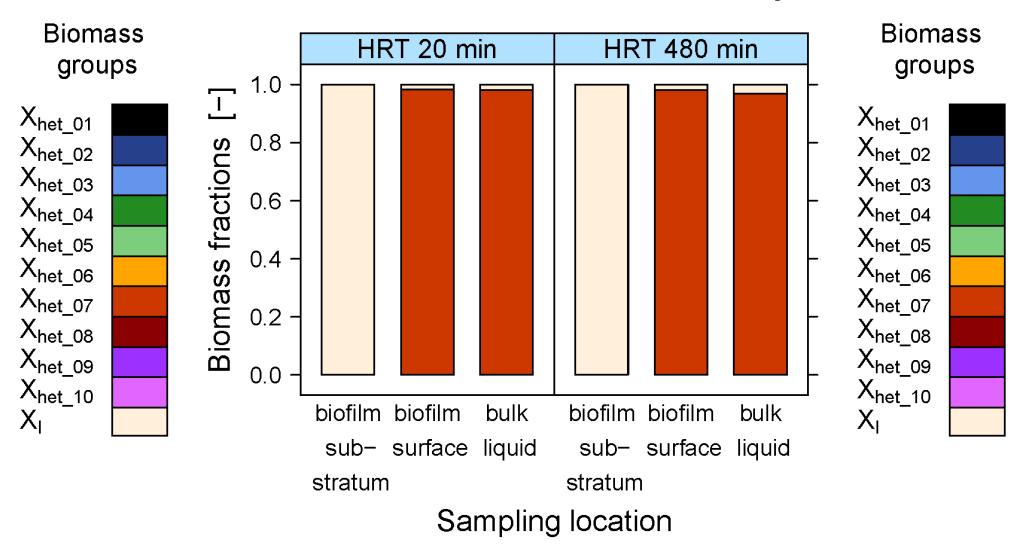

Biomass

groups

$X_{\text {het_01 }}$
$X_{\text {het_02 }}$
$X_{\text {het_03 }}$
$X_{\text {het_04 }}$
$X_{\text {het_05 }}$
$X_{\text {het_06 }}$
$X_{\text {het_07 }}$
$X_{\text {het_08 }}$
$X_{\text {het_09 }}$
$X_{\text {het_10 }}$
$X_{1}$

Figure 4: Biomass distributions at the biofilm substratum, the biofilm surface, and in the bulk liquid for a $\mu$ strategist as dominating bacterial group. Biomass distributions are given for days $1,3,7$, and 42 (end of the experiment) for HRTs of both 20 minutes and 8 hours (480 minutes). Heterotrophic bacteria 1 to 5 are K-strategists, heterotrophic bacteria 6 to 10 are $\mu$-strategists.

\section{REFERENCES}

Andrews, J.H. and Harris, R.F. (1986) R-selection and K-selection and microbial ecology. Advances in Microbial Ecology 9, 99-147.

Button, D.K. and Robertson, B.R. (1989) Kinetics of bacterial processes in natural aquatic systems based on biomass as determined by high-resolution flow cytometry. Cytometry 10(5), 558-563.

Nedwell, D.B. (1999) Effect of low temperature on microbial growth: lowered affinity for substrates limits growth at low temperature. FEMS Microbiology Ecology 30(2), 101-111.

R Development Core Team (2010) R: A language and environment for statistical computing, R Foundation for Statistical Computing, Vienna, Austria.

Ramirez, I., Volcke, E.I.P., Rajinikanth, R. and Steyer, J.P. (2009) Modeling microbial diversity in anaerobic digestion through an extended ADM1 model. Water Research 43(11), 2787-2800.

Reichert, P. (1998) AQUASIM 2.0 - User Manual, Computer program for the identification and simulation of aquatic systems, Swiss Federal Institute for Environmental Science and Technology (EAWAG), Dübendorf, CH.

Rochex, A., Masse, A., Escudie, R., Godon, J.J. and Bernet, N. (2009) Influence of abrasion on biofilm detachment: evidence for stratification of the biofilm. Journal of Industrial Microbiology \& Biotechnology 36(3), 467-470.

Saltelli, A., Chan, K. and Scott, E.M. (eds) (2000) Sensitivity analysis, John Wiley \& Sons Ltd.

Spear, R.C. and Hornberger, G.M. (1980) Eutrophication in peel inlet .2. Identification of critical uncertainties via generalized sensitivity analysis. Water Research 14(1), 43-49.

Wanner, O. and Gujer, W. (1984) Competition in biofilms. Water Science and Technology 17(2-3), 27-44.

Wery N, Bru-Adan V, Minervini C, Delgenes JP, Garrelly L \& Godon JJ (2008) Dynamics of Legionella spp. and bacterial populations during the proliferation of $L$. pneumophila in a cooling tower facility. Applied and Environmental Microbiology 74: 3030-3037. 